\title{
CORAK BUDIDAYA JENIS AVIFAUNA OLEH MASYARAKAT KOTA MANOKWARI DI PAPUA BARAT, INDONESIA
}

\section{REARING PERFORMANCES OF AVIFAUNA KEPT BY CITY COMMUNITY OF MANOKWARI IN WEST PAPUA, INDONESIA}

\section{DENY ANJELUS IYAI ${ }^{1}$, YUSAK SADA ${ }^{2}$, DWI NURHAYATI ${ }^{1}$, YUBELINCE Y. RUNTUBOI ${ }^{3}$, ELIESER V. SIRAMI $^{3}$, MELISA WORABAI $^{3}$, AISYAH BAUW $^{4}$, HANS MAMBOAI $^{5}$}

\author{
${ }^{1}$ Program Studi Budidaya Ternak. Jurusan Peternakan. Fakultas Peternakan. Universitas Papua. Jl. Gunung Salju, Amban. \\ Manokwari Papua Barat. Indonesia. Kode Pos 98314. \\ ${ }^{2}$ Dinas Peternakan dan Kesehatan Hewan Provinsi Papua Barat. Jl. BrigJen (Purn) A.O. Ataruri. Manokwari, Papua Barat \\ Indonesia. Kode Pos 98311 \\ ${ }^{3}$ Program Studi Konservasi. Jurusan Kehutanan. Fakultas Kehutanan. Universitas Papua. Jl. Gunung Salju, Amban. \\ Manokwari Papua Barat. Indonesia. Kode Pos 98314 \\ ${ }^{4}$ Program Studi Ekomoni Pembangunan, Jurusan Ekonomi. Fakultas Ekonomi dan Bisnis. Universitas Papua. Jl. Gunung \\ Salju, Amban. Manokwari Papua Barat. Indonesia. Kode Pos 98314. \\ ${ }^{5}$ Program Studi Agribisnis, Jurusan Sosial Ekonomi Pertanian. Fakultas Pertanian. Universitas Papua. Jl. Gunung Salju, \\ Amban. Manokwari Papua Barat. Indonesia. Kode Pos 98314. \\ *E-mail: $\underline{\text { d.iyai@unipa.ac.id }}$
}

\begin{abstract}
The public still over-exploits avifauna. Cultivation techniques of Avifauna species and how they are used are the focus of this study. The method used is descriptive method with survey techniques. Random sampling using interview and observation methods. Ten households as respondents were selected from the community who have a hobby of caring for wild animals in the city of Manokwari. The object of observation is the domestication of bird information maintained, hunting activities for the use of avifauna, housing systems, food, signs of estrus, disease and prevention and socioeconomic aspects. The results showed that the age of caregivers for the avifauna animal group was dominated by the 22-44 year age group. Avifauna animal keepers in Manokwari are dominated by the ASN and TNI/POLRI as many as 2 people, followed by groups of entrepreneurs, students and farmers as much as 10\%. Keepers have a high school education (50\%), followed by junior high school (40\%) and tertiary education (10\%). Avifauna cultivated are parrots, paradise birds, Victoria crowned pigeon, hornbills, eagles and cassowaries. Victoria crowned pigeon and cassowaries are starting to be difficult to find, which are categorized as being near threatened and least concerned. The cage materials used as cage walls are wood (100\%), the roof of the cage is made of zinc (100\%), and the cage floor used varies namely bamboo, wood, cement and concrete steel. Avifauna animals are obtained by buying and hunting. Utilization of avifauna includes the maintenance of pets, decoration and consumption. Taming is done by bathing the animal, given food (kitchen scraps), giving saliva and also by putting the animal in a cage. The duration of taming is 4.8 months ( 1 24 months). The community makes avifauna as an animal entertainment and decoration that has aesthetic value.
\end{abstract}

Keywords: avifauna, aesthetics, domestication, pet animals, wildlife.

\begin{abstract}
ABSTRAK
Masyarakat masih memanfaatkan jenis-jenis avifauna secara berlebihan. Teknik budidaya dari jenis avifauna dan bagaimana pemanfaatannya, merupakan focus dari kajian ini. Metode yang digunakan adalah metode deskriptif dengan teknik survei. Pengambilan sampel secara acak menggunakan metode wawancara dan observasi. Sebanyak 10 kepala keluarga sebagai responden dipilih dari masyarakat yang memiliki hobi memelihara satwa liar di kota Manokwari. Obyek pengamatan adalah proses domestikasi informasi burung yang dipelihara, kegiatan berburu pemanfaatan avifauna, sistim perkandangan, makanan, tanda-tanda estrus, penyakit dan pencegahan dan aspek sosial ekonomi. Hasil penelitian menunjukkan bahwa umur pemelihara untuk kelompok hewan avifauna didominasi oleh kelompok umur 22-44 tahun. Pekerjaaan para pemelihara satwa avifauna di Manokwari didominasi oleh ASN dan TNI/Polri sebanyak 2 orang diikuti oleh kelompok wiraswasta, pelajar dan petani sebanyak $10 \%$. Pemelihara memiliki pendidikan sekolah menengah atas (50\%), diikuti oleh sekolah menengah pertama (40\%) dan perguruan tinggi (10\%). Jenis avifauna yang dibudidaya adalah nuri, kakatua, cenderawasih, mambruk, rangkok, elang dan kasuari. Mambruk dan kasuri mulai sulit ditemukan yang dikategorikan statusnya menjadi near threatened dan least concern. Bahan kandang yang digunakan sebagai dinding kandang adalah berupa kayu (100\%), atap kandang terbuat dari seng (100\%), serta lantai kandang yang digunakan bervariasi yaitu bambu, kayu, semen dan besi beton. Satwa avifauna diperoleh dengan cara di beli dan berburu. Pemanfaatan avifauna meliputi pemeliharaan hewan kesayangan, hiasan dan konsumsi. Penjinakkan
\end{abstract}


dilakukan dengan memandikan hewan, diberikan makanan (sisa dapur), memberikan air liur dan juga dengan meletakkan hewan tersebut di dalam kandang. Lama waktu menjinakkan adalah 4.8 bulan (1-24 bulan). Masyarakat menjadikan avifauna sebagai hewan hiburan dana tau hiasan yang memiliki nilai estetika.

Kata kunci : avifauna, estetika, penjinakan, pet animal, satwa liar.

\section{PENDAHULUAN}

Indonesia merupakan salah satu negara Megabiodiversity di dunia dikarenakan tingginya kekayaan keragaman fauna (MacKinnon 1992). Keragaman biodiversiti ini dipengaruhi oleh wilayah yang luas, keadaan geografik, letak biogeografis dan ekosistem (Widjaya et al., 2014; Kartikasari et al., 2012; Kuswandi et al., 2015). Hal ini seperti yang dilaporkan oleh Arini (2011), Hidayat (2018), Kamaluddin et al. (2019) , Rahadian et al. (2019), dan Linggarjati et al. (2014). Secara astronomis, kawasan Papua merupakan provinsi yang berada paling timur dan termasuk wilayah negara Papua New Guinea. Kawasan yang panjangnya $2800 \mathrm{~km}$ dan lebarnya $750 \mathrm{~km}$ ini terbentang dari garis khatulistiwa sampai 12LS, dan 129-155 BT yang paling luas di kawasan tropis dunia. Dengan letak astronomis demikian, kawasan Papua memiliki beragam tipe ekosistim dan daerah biogeografis.

Kekayaan Biodiversiti di Papua memiliki keragaman tipe eskosistem yang di mulai dari daerah pantai, dataran rendah, pegunungan rendah sampai apda pegunungan tinggi. Keunikan tipe ekosistim tersebut merupakan habitat yang ideal bagi perkembangan kehidupan spesies fauna baik yang endemic maupun eksotik. Fauna burung yang ada di Papua memiliki keunikan tersendiri sehingga merupakan salah satu di antara kelima Bird centre (Anonimous, 1995). Lebih dari 700 jenis avifauna di Papua dibedakan menjadi 4 kelompok: 578 jenis berbiak di darat dan air tawar, 40 jenis burung laut, 56 jenis migran dari utara katulistiwa dan 34 jenis pengembara .

Sebagain besar jenis-jenis burung yang ada di Papua masih tergolong liar dan karenanya memiliki nilai eksotika yang tinggi. Oleh sebab itu banyak masyarakat memanfaatkan jenis-jenis burung tersebut secara berlebihan dengan mengadakan perburuan dan pengrusakan habitat alami. Jenisjenis burung yang ditangkap tersebut dimanfaatkan masyarakat untuk dikonsumsi, hiasan, dijual bahkan tidak jarang yang mengambilnya untuk dipelihara dalam rangka memperoleh pendapatan tambahan.
Dalam pemeliharaan satwa liar tersebut perlu dilakukan proses domestikasi agar satwa tersebut menjadi jinak, tenang dan lebih mudah dalam pemeliharaannya. Hewan-hewan yang didomestikasi tersebut harus mendapatkan sejumlah perubahan dalam pola kehidupan (pola tingkah laku) sebab masyarakat memelihara hewan tersebut untuk keuntungan ekonomi, sosial dan humaniora. Sejauhmana usaha-usaha pemeliharaan hewan yang diperoleh masyarakat untuk dibudidayakan dipenangkaran di kota Manokwari perlu untuk dipelajari dengan baik sehingga dapat menjadi catatan tersendiri dalam upaya pengawasan dan pembudidayaan satwa sebagai hewan kesukaan.

\section{METODE PENELITIAN \\ Metode dan Teknik Pengumpulan Data}

Metode yang digunakan dalam penelitian ini adalah deskriptif dengan teknik survey. Pengambilan sampel pada usaha domestikasi satwa liar dilakukan di Manokwari dengan menggunakan metode wawancara dan observasi. Sebanyak $10 \mathrm{KK}$ sebagai responden dipilih secara acak pada masyarakat yang memiliki hobby memelihara satwaliar di kota Manokwari. Sumber data diperoleh dari hasil interview dan studi pustaka (Moleong, 1991). Dalam penelitian ini obyek pengamatan adalah proses domestikasi beberapa jenis avifauna seperti nuri, kakatua, cenderawasih, mambruk, rangkok, elang dan kasuari. Variabel pengamatan yang digunakan meliputi informasi dasar pemelihara, jenis burung yang dipelihara, kegiatan berburu, pemanfaatan avifauna yang dipelihara, sistim perkandangan, makanan, tanda-tanda birahi, penyakit dan pencegahan dan aspek social-ekonomi.

\section{Analisis Data}

Data yang diperoleh selanjutnya dianalisa secara tabulasi dan deskriptif (Ott dan Longnecker 2001; Santoso 2012; Asra dan Sutomo 2016) untuk memperoleh gambaran obyektif kondisi satwaliar yang ada di Papua, khususnya Manokwari.

\section{HASIL \\ Karakteristik responden}


Identitas kepemilikan satwa avifauna di Manokwari dominan berada pada kisaran umur 22-44 tahun (70\%). Umur pemelihara kurang dari 22 tahun adalah sebesar $20 \%$ saja.

Tabel 1. Komposisi usia pemelihara hewan avifauna di Manokwari.

\begin{tabular}{ccc}
\hline $\begin{array}{c}\text { Kelompok umur } \\
\text { (tahun) }\end{array}$ & $\begin{array}{c}\text { Jumlah } \\
\text { (orang) }\end{array}$ & $\begin{array}{c}\text { Proporsi } \\
(\%)\end{array}$ \\
\hline$<22$ & 2 & 20 \\
$22-44$ & 7 & 70 \\
$>44$ & 1 & 10 \\
\hline
\end{tabular}

Diikuti dengan umur pemelihara $>45$ tahun sebanyak $10 \%$. Umur pemelihara satwaliar untuk kelompok hewan avifauna ini didominasi oleh kelompok umur 22-44 karena saat ini di Indonesia secara umum telah dikembangkan ajang lomba hewan bersuara (Nurdin, Nasihin, and Guntara 2017; Iskandar 2018; Wayne and Poerbantanoe 2015). Dengan demikian kelompok usia ini mendominasi pemeliharaan avifauna. Selain itu, dibutuhkan keterampulan dan pengetahuan khusus dalam usaha budidaya hewan avifauna karena hewan ini membutuhkan perawatan dan perhatian yang serius dan relative belum lazim dibudidayakan secara luas.

\section{Pekerjaan}

Pekerjaan para pemelihara satwa avifauna di Manokwari adalah didominasi oleh PNS/TNI/Polri sebanyak 2 orang. Selain itu, diikuti oleh kelompok wiraswasta, pelajar dan petani, masing-masing $10 \%$.
Tabel 2. Karaketeristik pemelihara

pekerjaan

\begin{tabular}{ccc}
\hline Pekerjaan & $\begin{array}{c}\text { Jumlah } \\
\text { (orang) }\end{array}$ & $\begin{array}{c}\text { Proporsi } \\
(\%)\end{array}$ \\
\hline Wiraswasta & 1 & 10 \\
Pelajar & 1 & 10 \\
Petani & 1 & 10 \\
Supir & 1 & 10 \\
PNS & 1 & 10 \\
Polisi & 1 & 10 \\
Meubel & 1 & 10 \\
Tidak bekerja & 3 & 30 \\
\hline
\end{tabular}

Hasil penelitian juga dijumpai pemelihara satwa avifauna yang tidak bekerja berjumlah tiga orang $(30 \%)$. Hasil kajian ini menunjukkan bahwa masyarakat menjadikan hewan avifauna sebagai hewan hiburan dan atau hiasan yang memiliki nilai estetika (J Iskandar and Iskandar 2018; Hasibuan, Ade, and Lubis 2015; Firdaus, Setiawan, and Rustiati 2014; Apriliano et al. 2018). Nilai estetika kelas hewan avifauna ini diperoleh masyarakat dari suara, kepintaran mengikuti aktifitas tertentu dan pola pewarnaan bulu hewan tersebut.

\section{Pendidikan}

Pola pendidikan pemelihara hewan kelas avifauna di Manokwari didominasi oleh pemelihara dengan pendidikan sekolah menengah atas (50\%), diikuti oleh sekolah menengah pertama $(40 \%)$ dan perguruan tinggi $(10 \%)$.

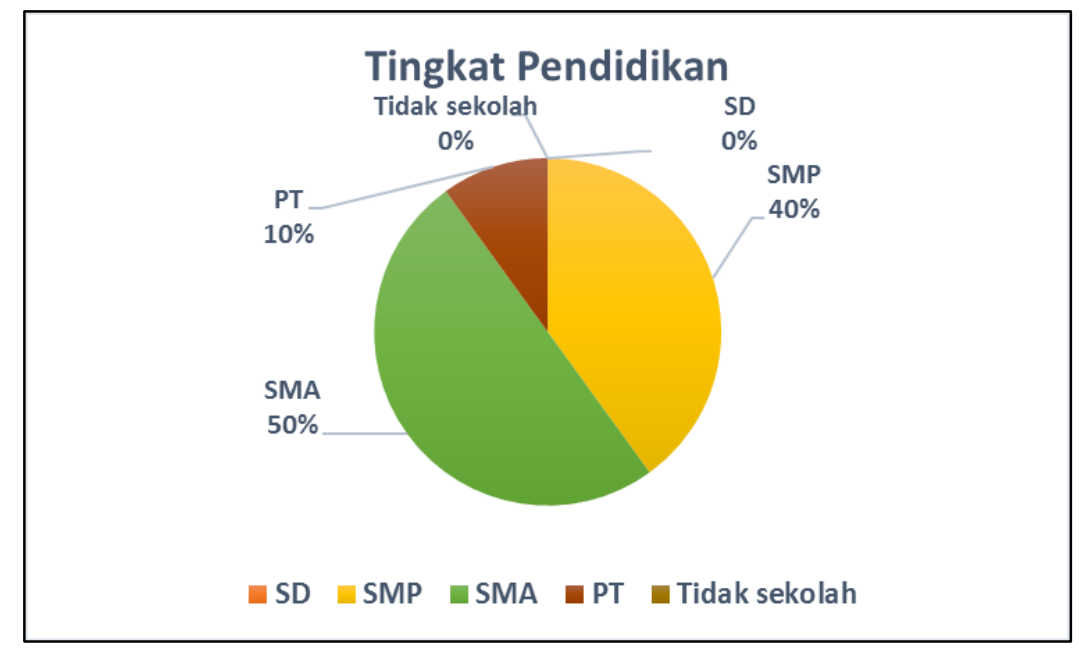

Gambar 1. Tingkat pendidikan para pemelihara hewan avifauna di Manokwari. 
Sementara pemelihara dengan tingkat pendidikan sekolah dasar (SD) dan tidak sekolah tidak dijumpai. Adanya tingkat pendidikan SD dan Tidak Sekolah yang dijumpai tidak berperan sebaga pemelihara hewan avifauna dapat dijadikan indikasi bahwa tingkat pendidikan menentukan pengetahuan dan keterampilan dalam melakukan sesuatu dalam hal ini kapasitas pemelihara hewan avifauna.

\section{Jenis Burung yang Dipelihara}

Jenis burung yang dominan dipelihara di kota Manokwari adalah jenis nuri, kakatua, cenderawasih, mambruk, rangkok, elang dan kasuari. Burung nuri masih memiliki populasi dan penyebaran di alam Papua yang cukup stabil pertumbuhan populasinya.

Tabel 3. Jenis burung yang dipelihara oleh masyarakat di kota Manokwari.

\begin{tabular}{llcc}
\hline Jenis burung & \multicolumn{1}{c}{ Nama Inggris } & $\begin{array}{c}\text { Jumlah } \\
\text { (Ekor) }\end{array}$ & Status IUCN* \\
\hline Nuri & Trichoglossus spp & 14 & Least Concern \\
Kakatua & Probosciger spp & 6 & Least Concern \\
Cenderawasih & Paradisaeidae & 3 & Least Concern \\
Mambruk & Goura spp & 1 & Near Threatened \\
Rangkok & Rhyticeros plicatus, J.R. Forst 1781 & 1 & Least Concern \\
Elang & Harpyopsis novaeguineae, Salvadori, 1875 & 1 & Vulnerable \\
Kasuari & Casuarius spp. & 1 & Least Concern \\
\hline
\end{tabular}

Sementara itu, kakatua dan cenderawasih cenderung berada pada hutan primer dataran rendah Papua. Saat ini kondisinya mulai terancam ketika pembalakan hutan alami terjadi. Mambruk dan kasuari mulai terasa sulit ditemukan. Kedua jenis hewan avifauna ini hidup terisolir pada hutan primer yang jauh dari gangguan manusia. Populasi dari kedua hewan avifauna ini juga mengalami penurunan yang pesat ketika pembukaan hutan ditujukan pada habitat dari hewan ini.

\section{Kegiatan pengelolaan}

Dalam aspek pengelolaan, indikator yang disajikan adalah aspek budidaya, kegiatan berburu, pemanfaatan dan upaya penjinakkan.

\section{Aspek budidaya}

Hasil penelitian menunjukkan bahwa bahan kandang yang digunakan sebagai dinding kandang adalah berupa kayu (100\%). Atap kandang terbuat dari seng (100\%), serta lantai kandang yang digunakan bervariasi yaitu bambu, kayu, semen dan besi beton.

Tabel 4. Karakteristik kandang yang digunakan pemelihara hewan avifauna

\begin{tabular}{|c|c|c|c|c|c|c|c|c|}
\hline \multirow{2}{*}{$\begin{array}{c}\text { Pemelih } \\
\text { ara }\end{array}$} & \multicolumn{3}{|c|}{ Bahan Kandang } & \multicolumn{3}{|c|}{$\begin{array}{c}\text { Ukuran kandang } \\
(\mathrm{cm})\end{array}$} & \multirow{2}{*}{$\begin{array}{l}\text { Jarak dari } \\
\text { Rumah }(\mathrm{cm})\end{array}$} & \multirow[t]{2}{*}{ Fasilitas } \\
\hline & DK & AK & LK & $\mathrm{P}$ & $\mathrm{L}$ & $\mathrm{T}$ & & \\
\hline 1 & Kayu & 0 & Bambu & 30 & 50 & 20 & Di dalam rumah & Tempat makan \& minum \\
\hline 2 & Kayu & & Kayu & 90 & 40 & 25 & Di dalam rumah & Tempat makan \& minum \\
\hline 3 & Kayu & Seng & Tanah & 80 & 60 & 100 & 500 & tempat makan, minum \& bertengger \\
\hline 4 & Kayu & 0 & 0 & 0 & 0 & 0 & 0 & 0 \\
\hline 5 & Kayu & Seng & Semen & 88 & 144 & 164 & 100 & $\begin{array}{l}\text { tempat makan, minum \& bertengger } \\
\text { serta sarang }\end{array}$ \\
\hline 6 & Kayu & Seng & Semen & 70 & 55 & 60 & 100 & tempat makan, minum \& bertengger \\
\hline 7 & Kayu & Seng & $\begin{array}{l}\text { Besi } \\
\text { beton }\end{array}$ & 100 & 100 & 200 & 100 & Tempat makan \& minum \\
\hline 8 & Kayu & 0 & 0 & 0 & 0 & 0 & 0 & 0 \\
\hline 9 & Kayu & 0 & 0 & 0 & 0 & 0 & 0 & 0 \\
\hline 10 & Kayu & Seng & Semen & 100 & 80 & 100 & 200 & tempat makan, minum \& bertengger \\
\hline
\end{tabular}

Untuk ukuran kandang yang digunakan pemelihara jenis hewan ini relative bervariasi yaitu dari $30 \mathrm{~cm}$ x $50 \mathrm{~cm}$ x $20 \mathrm{~cm}$ untuk ukuran minimal sampai dengan $100 \mathrm{~cm}$ x $100 \mathrm{~cm}$ x 200 $\mathrm{cm}$, untuk ukuran maksimal. Jarak dari rumah berkisar dari 100 sampai $500 \mathrm{~cm}$. Ditemukan 
juga bahwa masih dijumpainya hewan avifauna yang dipelihara di dalam rumah. Fasilitas kandang yang disediakan pemelihara relatif seragam yaitu tempat makan, tempat minum dan bertengger.

\section{Sumber hewan peliharaan}

Kami juga tertarik untuk mengetahui sumber/asal hewan yang dipelihara. Hasil penelitian ditemukan bahwa asal hewan avifauna diperoleh dengan cara di beli dan di buru.

Tabel 5. Sumber hewan peliharaan di Manokwari

\begin{tabular}{|c|c|c|c|c|c|c|c|c|c|}
\hline \multirow{3}{*}{ Pemelihara } & \multicolumn{2}{|c|}{ Asal burung } & \multirow{3}{*}{$\begin{array}{l}\text { Metode } \\
\text { berburu }\end{array}$} & \multirow{3}{*}{$\begin{array}{c}\text { Alat } \\
\text { berburu }\end{array}$} & \multirow{2}{*}{\multicolumn{2}{|c|}{$\begin{array}{l}\text { Jumlah pemburu } \\
\text { (orang }\end{array}$}} & \multirow{3}{*}{$\begin{array}{c}\text { Frekuensi } \\
\text { berburu }\end{array}$} & \multirow{3}{*}{$\begin{array}{l}\text { Lokasi } \\
\text { berburu }\end{array}$} & \multirow{3}{*}{$\begin{array}{l}\text { Jarak } \\
(\mathrm{km})\end{array}$} \\
\hline & \multirow{2}{*}{ Beli } & \multirow{2}{*}{ Berburu } & & & & & & & \\
\hline & & & & & Orang & Kelompok & & & \\
\hline 1 & 0 & 1 & jerat & Jerat nelon & 0 & 1 & $2 \times 1$ & HP & \pm 20 \\
\hline 2 & 0 & 1 & tembak & $\begin{array}{c}\text { senapan } \\
\text { api }\end{array}$ & 1 & 0 & $1 \mathrm{x} 1$ & 0 & 0 \\
\hline 3 & 1 & 0 & 0 & 0 & 0 & 0 & 0 & 0 & 0 \\
\hline 4 & 0 & 1 & jerat & $\begin{array}{c}\text { jerat } \\
\text { bambu }\end{array}$ & 1 & 0 & $1 \times 1$ & $\mathrm{HP}$ & \pm 6 \\
\hline 5 & 1 & 0 & 0 & 0 & 0 & 0 & 0 & 0 & 0 \\
\hline 6 & 0 & 1 & tembak & tembak & 1 & 0 & $1 \times 1$ & $\mathrm{HP}$ & \pm 11 \\
\hline 7 & 1 & 0 & 0 & 0 & 0 & 0 & 0 & 0 & 0 \\
\hline 8 & 1 & 0 & 0 & 0 & 0 & 0 & 0 & 0 & 0 \\
\hline 9 & 1 & 0 & 0 & 0 & 0 & 0 & 0 & 0 & 0 \\
\hline 10 & 1 & 0 & 0 & 0 & 0 & 0 & 0 & 0 & 0 \\
\hline
\end{tabular}

Keterangan: $\mathrm{HP}=$ hutan primer

Metode berburu hewan ini adalah dengan menggunakan jerat, dan tembak menggunakan senjata api. Jumlah orang yang berburu adalah secara perorangan dan kelompok. Rata-rata frekuensi berburu juga 1 kali dalam 1 minggu dana tau 2 kali per minggu. Lokasi dimana hewan ini diburu adalah umumnya di hutan primer. Hutan primer yang ada di Manokwari berjarak 6-20 km.

\section{Pemanfaatan}

Tujuan pemanfaatan hewan avifauna meliputi pemeliharaan hewan kesayangan (pet animal), hiasan dan dikonsumsi.

Table 6. Pemanfaatan hewan avifauna

\begin{tabular}{lcccc}
\hline \multicolumn{1}{c}{ Jenis burung } & Tujuan pemanfaatan & $\begin{array}{c}\text { Bagian yg } \\
\text { dimanfaatkan }\end{array}$ & $\begin{array}{c}\text { Jumlah yg } \\
\text { dimanfaatkan }\end{array}$ & Cara pemanfaatan \\
\hline Nuri & Kesayangan dan konsumsi & $\begin{array}{c}\text { Daging dan kuit } \\
\text { tubuh } \\
\text { Kakatua }\end{array}$ & $\begin{array}{c}\text { Seluruh tubuh } \\
\text { kecuali paruh } \\
\text { Kesayangan }\end{array}$ & $\begin{array}{c}\text { olah bahan makan dan } \\
\text { hiasan }\end{array}$ \\
$\begin{array}{l}\text { Cenderawasih } \\
\text { Mambruk }\end{array}$ & Hiasan & tubuh burung & $\begin{array}{c}\text { Seluruh tubuh } \\
\text { kecuali paruh }\end{array}$ & diawetkan \\
$\begin{array}{l}\text { Rangkok } \\
\text { Elang }\end{array}$ & Hiasan & & \\
Kasuari & $\begin{array}{l}\text { Hiasan } \\
\text { Hiasan }\end{array}$ & kesayangan, hiasan dan \\
konsumsi & bulu dan daging & seluruh tubuh & $\begin{array}{c}\text { diolah jadi makanan dan } \\
\text { bulu untuk kipas }\end{array}$ \\
\hline
\end{tabular}

Bagian tubuh hewan yang dimanfaatkan oleh konsumer adalah tubuh berupa daging dan kulit serta bulu dan kombinasinya (Hidayat 2018; Julyanto 2016; Kamaluddin, Winarno, and Dewi 2019; Nuraini, Saputra, and Abdullah 2018; Linggarjati et al. 2014; J Iskandar 2018; Hasibuan, Ade, and Lubis 2015; Firdaus, Setiawan, and Rustiati 2014). Jumlah yang dimanfaatkan adalah seluruh tubuh hewan kecuali paruh. Cara pemanfaatan dilakukan dengan mengolah bahan makanan dan digunakan sebagai hiasan .

\section{Upaya penjinakkan}

Pemelihara hewan kelas avifauna terdiri dari anak remaja, ayah dan ibu serta kombinasi dari ketiganya. Umumnya ditemukan remaja mendominasi sebagai pemelihara kelas 
avifauna. Hal ini dikarenakan tujuan pemeliharaan ini dilakukan sebagai hewan kesayangan (pet animal).

Metode penjinakkan hewan avifauna pada awal pemeliharaannya dilakuan dengan memandikan hewan tersebut. Selain itu, dan diberikan makanan (sisa dapur). Selain itu, ada pemelihara yang memberikan air liur untuk membantu meningkatkan hubungan emosional hewan dengan pemeliharanya. Perlakukan lain yang dilakukan pemelihara juga dengan meletakkan hewan tersebut di dalam kandang. Hal ini dilakukan untuk membatasi ruang gerak dan agresifitas hewan tersebut.

Tabel 7. Metode, periode dan tingkahlaku penjinakan hewan avifauna.

\begin{tabular}{|c|c|c|c|c|c|c|c|}
\hline \multirow[b]{2}{*}{$\begin{array}{l}\text { Respond } \\
\text { en }\end{array}$} & \multirow[b]{2}{*}{ Pemelihara } & \multirow[b]{2}{*}{ Metode penjinakkan } & \multicolumn{3}{|c|}{ LP } & \multicolumn{2}{|c|}{ Tingkahlaku } \\
\hline & & & $\begin{array}{c}\mathrm{H} \\
\mathrm{r}\end{array}$ & $\begin{array}{c}\mathrm{M} \\
\mathrm{g}\end{array}$ & $B \ln$ & Sebelum & Sesudah \\
\hline 1 & Remaja & $\begin{array}{l}\text { dimandikan, diberikan } \\
\text { makanan }\end{array}$ & 0 & 0 & 1 & Liar & Jinak, tenang \\
\hline 2 & Remaja & makanan sisa dan air liur & 0 & 0 & 2 & Liar & Jinak \\
\hline 3 & Remaja & mandikan dan kandang & 0 & 0 & 2 & Agak liar & Jinak \\
\hline 4 & $\begin{array}{l}\text { Remaja } \\
\text { /ayah/ibu }\end{array}$ & makanan sisa & 0 & 0 & 2 & Agak liar & Jinak \\
\hline 5 & Remaja /ibu & dikandangkan & 0 & 0 & 4 & $\begin{array}{l}\text { Liar, suka } \\
\text { menggigit }\end{array}$ & $\begin{array}{c}\text { Jinak, tidak menggigit, } \\
\text { bermain }\end{array}$ \\
\hline 6 & Bapak & $\begin{array}{l}\text { kandang dan makanan } \\
\text { sisa }\end{array}$ & 0 & 0 & 2 & Liar, takut & $\begin{array}{l}\text { Jinak, tidak takut dan } \\
\text { suka bermain }\end{array}$ \\
\hline 7 & Bapak & Diberikan makanan sisa & 0 & 0 & 24 & $\begin{array}{l}\text { Liar, suka } \\
\text { menendang }\end{array}$ & jinak, tidak lari \\
\hline 8 & Bapak/ Remaja & Sudah jinak & 0 & 0 & 0 & 0 & 0 \\
\hline 9 & $\mathrm{Ibu}$ & makanan sisa & 0 & 0 & 6 & Tidak liar & Jinak dan berbicara \\
\hline 10 & Bapak & dikandangkan & 0 & 0 & 5 & Liar & Jinak dan suka bermain \\
\hline & Rataan & & & & 4.8 & & \\
\hline
\end{tabular}

Lama waktu yang digunakan untuk penjinakan (domestikasi) rata-rata adalah 4,8 bulan (1-24 bulan). Dari data di atas diketahui bahwa dengan perlakukan memandikan hewan, lama waktu penjinakkan berkisar antara 1-2 bulan (Responden 1 dan 3). Pemberian sisa makanan dapur sedikit lebih lama 2-24 bulan. Dengan metode dikandangkan, lama waktu penjinakkan berada pada range 2-5 bulan (Responden 3, 5, dan 10). Perubahan tingkah laku yang terjadi sebelum dan setelah adalah dari sifat dari agak liar, liar, takut, menggigit dan suka menendang berubah menjadi jinak, tenang, tidak menggigit, jinak, tidak lari dan dapat berbicara dan suka bermain. Upaya domestikasi hewan avifauna ini penting dan strategis untuk dilakukan (Widjaya et al. 2014; Mangunjaya et al. 2014).

\section{PEMBAHASAN}

Adanya animo pencinta hewan di Manokwari sebagai ibu kota Provinsi Papua Barat dengan visi provinsi konservasi dan provinsi pembanguan keberlanjutan (sustainable development province) telah memberikan sinyal akan pentingnya pengelolaan flora dan fauna eksotis di Tanah Papua Barat (Pattiselanno 2003; Pattiselanno and Arobaya 2013; Abbott and van Kooten 2011; Scherr and Mcneely 2008; Mateo and Editors 2016; Walujo 2011). Dari segi masyarakat, diperlukan pembinaan dan pendampingan serta monitoring yang intens tentang sejauhmana pola pemanfaatan satwa endemik dan eksotis di Manokwari, Papua Barat. Beberapa hewan avifauna yang selama ini dilindungi oleh negara melalui undangundang dan peraturan relevan lainnya (Pattiselanno et al. 2015; Mangunjaya et al. 2014; KEHATI 2017; Fuad 2004; Widjaya et al. 2014) menjadi perhatian serius bagi instansi teknis pengelola.

Jenis avifauna yang dipelihara di kota Manokwari terdapat beberapa satwa yang dikategorikan terancam punah seperti mambruk dan hewan yang rentan punah seperti elang. Selain itu satwa avifauna seperti cenderawasih masih dipelihara oleh penduduk kota Manokwari. Kasuari, cenderawasih, kakatua, dan nuri masuk dalam kategori yang rentan (Weyah et al., 2018; Kartikasari et al., 2012; Pattiselanno and Arobaya, 2013; Keiluhu, 2013). Pemeliharaan satwa avifauna ini secara undang-undang wajib mematuhi peraturan dan memiliki ijin tertulis. Penduduk wajib menyediakan dan memberikan kenyamanan dan 
mematuhi hak-hak hewan (animal right) dan kesejahteraan hewan (animal welfare) (Lindenmayer, 2011; Damania et al., 2005). Dari dari observasi, keberadaan hewan yang dibudidaya ini belum banyak memberikan kenyamanan dan kelayakan dalam upaya budidaya. Selain itu, kontrol dari instansi teknis seperti kantor BKSDA, karantina dan klinik hewan melalui dokter hewan belum banyak dilibatkan dalam memantau kelangsungan hidup satwa avifauna.

Dari aspek pengelolaan, di Manokwari sendiri sebagai Ibu kota Provinsi Papua Barat, alokasi lahan untuk tujuan perawatan, keselamatan dan kesejahteraan hewan seperti taman burung atau taman satwa belum ada. Hal ini penting sekali disediakan pemerintah daerah. Tujuannya selain memberikan pelayanan kesehatan hewan peliharaan juga untuk tujuan budidaya dan pelestarian (Kartikasari et al., 2012). Selain itu, taman-taman ini dapat mempercepat pelestarian satwaliar pada habitatnya. Hal ini penting karena saat ini perubahan fungsi ekosistim di alam dan hidupan liar sangat tinggi. Lahan yang ada saat ini telah banyak dialihfungsikan menjadi lahan perkebunan, lahan pertanian, dan lahan pembangunan infrastruktur lainnya.

Budidaya satwaliar dapat dilakukan pada habitatnya secara incitu juga dapat dilakukan di luar habitatnya secara excite (Arini, 2011). Dengan demikian, upaya yang dilakukan oleh masyarakat yang memiliki satwa piaraan diharapkan untuk dapat merawat hewan piaraan sesuai dengan kelayakan dan aturan yang ditetapkan oleh undang-undang perlindungan satwaliar. Oleh karena itu, dituntut pemahaman lebih terhadap pengetahuan hewan dan hidupan alamnya. Pembinaan dan pendampingan dalam pemeliharaan dan perawatan hewan pun semakin penting untuk dilakukan.

Upaya penjinakkan dan pengelolaan dalam teknik budidaya satwaliar penting dilakukan. Keterlibatan semua komponen stakeholder penting dilakukan. Budidaya satwaliar di Papua berjalan lambat karena keterlibatan dan komitmen pemerintah masih kurang. Alokasi dana pengelolaan satwaliar dirasakan masih rendah (KEHATI, 2017). Padahal di beberapa daerah satwa endemik terutama avifauna telah menjadi maskot penting. Misalnya di Papua barat, lambang daerah adalah kasuari. Manokwari sendiri memiliki maskot burung mambruk (Hidayat, 2018). Namun sampai saat ini, upaya-upaya strategis dalam pengembangan dan budidaya satwa masih kurang. Padahal lembaga riset seperti Universitas Papua telah menghasilkan banyak sumber data yang mampu mendukung upaya-upaya penjinakan dan budidaya satwaliar.

Kedepannya, dibutuhkan komitmen dan keselaran program-program dan aksi-aksi nyata yang mampu melakukan pengelolaan dan pemanfaatan satwa liar di Tanah Papua. Melalui lembaga Litbang daerah, universitas dan lembaga pengelola sumberdaya alam seperti Litbang Kehutanan, BKSDA dan UNIPA perlu didukung oleh pemerintah daerah.

\section{KESIMPULAN}

Dari hasil penelitian ini dapat disimpulkan bahwa hewan avifauna yang dominan dipelihara di kota Manokwari adalah jenis nuri, kakatua dan cenderawasih. Pendidikan pemelihara adalah sekolah menengah atas, diikuti oleh pendidikan SMP dan sedikit yang mengenyam pendidikan perguruan tinggi. Mambruk dan kasuri mulai terasan sulit ditemukan yang dikategorikan statusnya menjadi near threatened dan least concern. Bahan dinding kandang berupa kayu, atap kandang dari seng, serta lantai kandang bervariasi dari bambu, kayu, semen dan besi beton. Satwa avifauna umumnya diperoleh dengan cara membelinya dengan tunai dan di buru sendiri. Pemanfaatan avifauna meliputi pemeliharaan hewan kesayangan, hiasan dan konsumsi. Domestikasi dilakukan dengan memandikan hewan, diberikan makanan (sisa dapur), memberikan air liur dan juga dengan meletakkan hewan tersebut di dalam kandang. Lama waktu menjinakkan adalah 4.8 bulan (124 bulan). Masyarakat menjadikan avifauna sebagai hewan hiburan dan atau hiasan yang memiliki nilai estetika.

\section{UCAPAN TERIMAKASIH}

Penulis menyampaikan terimakasih dan penghargaan yang tinggi kepada komunitas pencinta hewan di Manokwari yang telah bekerja sama memberikan akses dalam pengambilan data lapangan. Kepada semua pihak yang mendukung terlaksananya kegiatan riset ini disampaikan terimakasih.

\section{DAFTAR PUSTAKA}

ABBOTT, BRANT, AND G. CORNELIS VAN KOOTEN. 2011. "Can Domestication of Wildlife Lead to 
Conservation? The Economics of Tiger Farming in China." Ecological Economics 70 $721-28$ https://doi.org/10.1016/j.ecolecon.2010.11 .006 .

APRILIANO, AMANDA, CHAIRUL ANWAR, SUCI WULAN PAWHESTRI, AND RINA BUDI SATIYARTI. 2018. "Keanekaragaman Burung Di Kampus UIN Raden Intan Lampung." BIOSFER Jurnal Tadris Pendidikan Biologi 9 (2): 193-203.

ARINI, D.I.D. 2011. “Avifauna Penghuni Hutan Kobe Kawasan Taman Nasional Aketajawe." Info BPK Manado, 2011.

ASRA, ABUZAR, AND SLAMET SUTOMO. 2016. Pengantar Statistika I. 1 st ed. Jakarta: PT. Rajagrafindo Persada.

BASKIN, LEONID, AND LEONID BASKIN. N.D. "Hunting as Sustainable Wildlife Management Hunting as Sustainable Wildlife Management" 41 (4): 173-80.

DAMANIA, R., E. J. MILNER-GULLAND, AND D. J. CROOKES. 2005. "A Bioeconomic Analysis of Bushmeat Hunting." Proceedings of the Royal Society B: Biological Sciences 272 (1560): 259-66. https://doi.org/10.1098/rspb.2004.2945.

FIRDAUS, A.B, A SETIAWAN, AND E.L RUSTIATI. 2014. "Keanekaragaman Spesies Burung Di Repong Damar Pekon Pahmungan Kecamatan Pesisir Tengah Krui Kabupaten Lampung Barat.” Jurnal Sylva Lestari 2 (2): 1-6.

FUAD, FOKKY. 2004. "Perlindungan Keanekaragaman Hayati Indonesia Dari Dampak Negatif Pengembangan" 1 (3).

HASIBUAN, M.I, F.Y ADE, AND R.R LUBIS. 2015. "Kabupaten Rokan Hulu Provinsi Riau." E-Jurnal Mahasiswa Biologi FKIP Univ. Pasir Pangaraian 1 (1): 12-13.

HIDAYAT, OKI. 2018. "Jenis-Jenis Tambahan Avifauna Hutan Penelitian Oilsonbai." Warta Cendana, 2018. http://www.foristkupang.org.

ISKANDAR, J, AND B.S ISKANDAR. 2018. "Pemanfaatan Aneka Ragam Burung Dalam Kontes Burung Kicau Dan Dampaknya Terhadap Konservasi Burung Di Alam : Studi Kasus Di Kota Bandung, Jawa Barat Benefit of Various Birds in the Song-Bird Contest and Its Impact to Bird Conservation in Nature:" In Pros Sem
Nas Masy Biodiv Indon, 747-52. https://doi.org/10.13057/psnmbi/m010411

ISKANDAR, JOHAN. N.D. "Dilema Antara Hobi Dan Bisnis Perdagangan Burung Serta Konservasi Burung," 180-85.

JULYANTO. 2016. "Studi Populasi Burung Famili Ardeidae Di Rawa Pcaing Desa Kibang Pacing Kecamatan Manggala Timur Kabupaten Tulang Bawang Provinsi Lampung."

KAMALUDDIN, A, G.D WINARNO, AND B.S DEWi. 2019. "Keanekaragaman Jenis Avifauna Di Pusat Latihan Gajah ( PLG) Taman Nasional Way Kambas Diversity of Avifauna at the Elephant Training Center." Jurnal Sylva Lestari 7 (1): 1021. https://doi.org/http://dx.doi.org/10.23960/j s11710-21.

KARTIKASARI, S.N., A.J. MARSHALL, AND B.M. BEEHLER. 2012. Seri Ekologi Indonesia, Jilid VI: Ekologi Papua. VI. Jakarta. www.obor.or.id.

KEHATI. 2017. "Annual Report KEHATI 2017." Jakarta. http://www.kehati.or.id.

KEILUHU, HENDERINA JOSEFINA. 2013. "The Impact of Hunting on Victoria Crowned Pigeon (Goura Victoria: COLUMBIDAE) in the Rainforests of Northern Papua, Indonesia."

KUSWANDI, R, N SUPRIYATNO, AND R SADONO. 2015. "Keanekaragaman Struktur Tegakan Hutan Alam Bekas Tebangan Berdasarkan Biogeografi Di Papua ( Diversity of Stand Structure in Logged-Over Forest Based on Papua Biogeography )." J. Manusia Dan Lingkungan 22 (2): 151-59. https://doi.org/10.22146/jml.18737.

LINDENMAYER, DAVID B. 2011. What Makes a Good Farm for Wildlife? Australia: CSIRO Publishing.

LINGGARJATI, B.D, N.K DEWI, U.N KHASANAH, AND YULIANA. 2014. "Diversitas Jenis Dan Kemelimpahan Avifauna Di Sub Urban Kota Madiun Bagian Barat." Jurnal Florea 1 (2): 1-7.

MAAS, B, T TSCHARNTKE, TJOA A, S SALEH, AND N EDY. 2017. Effects of Ecosystem Services Provided by Birds and Bats in Smallholder Cacao Plantations of Central Sulawesi Dampak Jasa Ekosistem Yang Diberikan Oleh Burung Dan Kelelawar Di Kebun Kakao Rakyat Di 
Sulawesi Tengah.

MACKINNON, K. 1992. Nature's Treasurehouse the Wildlife of Indonesia. Jakarta: Gramedia Pustaka Utama.

MANGUNJAYA, F, H.S PRABOWO, I.S.L TOBING, A.S ABBAS, C SALEH, SUNARTO, M HUDA, AND T.M MULYANA. 2014. Pelestarian Satwa Langka Untuk Keseimbangan Ekosistem. Jakarta: Lembaga Pemuliaan Lingkungan Hidup dan Sumber daya alam Majelis Ulama Indonesia.

MATEO, RAFAEL, AND JESUS T GARCIA EDITORS. 2016. "Current Trends in Wildlife." In Wildlife Research Monographs 1, 299. Switzerland: Springer Nature.

MOLEONG, LEXY J. 1991. Metode Penelitian Kualitatif. 3rd ed. Bandung: Remaja Rosdakarya Offset, Bandung.

NURAINI, F SAPUTRA, AND S ABDULLAH. 2018. Keanekaragaman Burung Di Taman Nasional Bogani Nani Wartabone.

NURDIN, I NASIHIN, AND A.Y GUNTARA. 2017. "Pemanfaatan Keanekaragaman Jenis Burung Berkicau Dan Upaya Konservasi Pada Kontes Burung Berkicau Di Kabupaten Kuningan Jawa Barat Nurdin 1) Iing Nasihin 2) Asep Yuda Guntara 3)." Winaraksa 11 (1): 1-5.

OTT, R. LYMAN, AND MICHAEL LONGNECKER. 2001. An Introduction to Statistical Methods and Data Analisys. 5th ed. USA: Duxbury.

PATTISELANNO, F. 2003. "The Wildlife Hunting in Papua." Biota 11 (1): 60-61. https://doi.org/https://doi.org/10.24002/bio ta.v11i1.2824.

Pattiselanno, F, and AYS Arobaya. 2013. "Managing Tropical Forest for Indonesian Papuan's Livelihood Papua: Centre of Biodiversity and Cultural Diversity Native Papuans and Forests." In Institute of Foresters of Australia National Conference, 207-15.

PATTISELANNO, F, J MANUSAWAI, AYS AROBAYA, AND $\mathrm{H}$ MANUSAWAI. 2015. "Pengelolaan Dan Konservasi Satwa Berbasis Kearifan Tradisional Di Papua." J. Manusia Dan Lingkungan 22
(1): 106-12.

RAHADIAN, R, H WIRADARMA, A KURNIAWAN, AND I.M TAMAR. 2019. "The Species Diversity of Avifauna in Bukit Cinta Klaten in Supporting the Development of Birdwatching Area of Gunung Gajah Village Klaten The Species Diversity of Avifauna in Bukit Cinta Klaten in Supporting the Development of Birdwatching Area of Gunung." In INSPINSA 2018, 9. https://doi.org/10.1088/17426596/1217/1/012164.

SANTOSO, S. 2012. Aplikasi SPSS Pada Statistik Non Parametrik. 1st ed. Jakarta: Gramedia.

SCHERR, SARA J, AND JEFFREY A MCNEELY. 2008. "Biodiversity Conservation and Agricultural Sustainability: Towards a New Paradigm of " Ecoagriculture ' Landscapes," no. July 2007: 477-94. https://doi.org/10.1098/rstb.2007.2165.

TABBA, S, AND L NURRANI. 2016. "Tipologi Zona Dan Tutupan Lahan Distribution Of Avifauna In Aketajawe Lolobata National Park Based On." Jurnal WASIAN 3 (1): 25-38.

WALUJO, E.B. 2011. "Keanekaragaman Hayati Untuk Pangan." In KIPNAS X. LIPI, 1-9.

WAYNE, B.M, AND B POERBANTANOE. 2015. "Pasar Burung Surya Di Bratang, Surabaya." Jurnal EDimensi Arsitektur III (2): 241-48.

WEYAH, WES, HJ KEILUHU, AND AK KARIM. 2018. "Wildlife Use in Lapua Community of Kaureh, Papua." Jurnal Biologi Udayana 22 (2): 51-58. https://doi.org/https://doi.org/10.24843/JB IOUNUD.2018.v22.i02.p01.

Widjaya, E.A., Y. Rahayuningsih, J.S. Rahajoe, R. Ubaidillah, I. Maryanto, W. Walujo, and G. Semiadi. 2014. Kekinian Keanekaragaman Hayati Indonesia 2014. LIPI. 